\title{
Bovine Cysticercosis and Human Taeniosis in Adama Town, Oromia Region, Ethiopia
}

Yacob Hailu Tolossa*, Ahmed Taha, Getachew Terefe and Tariku Jibat

Addis Ababa University, College of Veterinary Medicine and Agriculture, Debre-zeit-34, Ethiopia

\begin{abstract}
A cross-sectional study was conducted in cattle slaughtered at Adama municipal abattoir in southwest Shoa zone of Oromia region to estimate the prevalence of bovine cystiercosis using routine meat inspection method and questionnaire surveys were undertaken to assess the status of human taeniosis and associated risk factors. Out of 384 carcasses examined, $2.6 \%$ were to be infected with Cysticercus bovis (C. bovis). Among positive cases for $C$. bovis, $78 \%$ were viable while it was more prevalent in the tongue and triceps muscle $(40 \%, 24 \%)$ than in the liver masseter muscle $(10 \% 6 \%)$ respectively. Based on the questionnaire survey, Taenia saginata (T. saginata) is a wide spread problem in Adama town where Out of 200 respondents $44 \%$ of the respondents had contracted $T$. saginata at least once in the past years. The prevalence of taeniosis was significantly higher $(p<0.000)$ in the raw meat consumers as compared to those consuming cooked meat. The annual taenicidal drug treatment cost by prescription in the study area from 2012-2014 was 378,609.66 Ethiopian birr which is equivalent to 18930.48 USD. The drug inventory clearly demonstrated the economic significance of $T$. saginata in the study area. Among respondents $85 \%$ of them do have a knowledge that taeniosis is a zoonotic disease transmitted through consumption of raw beef meat. In conclusion, $C$. bovis and $T$. saginata are among important health zoonotic cestodes in the study areas. Improvement in meat inspection procedures and sanitary conditions as well as public education as to decrease negligence among public should get due attention.
\end{abstract}

Keywords: Cysticercosis; Cattle; Human; Adama; Oromia; Ethiopia

\section{Introduction}

Taenia saginata/taeniosis/bovine cysticercosis is one of the major parasitic diseases, transmitted by eating raw or undercooked meat infected with cyst stages of these parasites. It does not only lead to economic loses, but also adversely affect the public health [1].

Taenia saginata is a cosmopolitan parasitic disease found in industrialized countries as well as in developing countries. It is also more common in populations/age groups that consume raw or undercooked beef [2]. In Eastern African countries like Ethiopia up to $70 \%$ of the population reports to have been infected with a tapeworm [3] while in developed western countries much lower prevalence $(0.01 \%$ to $10 \%)$ were recorded [1]. Similarly, bovine cysticercosis, the source of infection for human beings, is highly prevalent in developing like Ethiopia. The prevalence of bovine cysticercosis in Ethiopia reported so far varies from relatively lower prevalence of $3.1 \%$ in central Ethiopia [4] to as high as 26.2\% at Awassa [5] whereas in Europe it ranges from $0.007 \%$ to $6.8 \%$ [6]. Differences in geographical isolates of the parasite and in the breed and age of cattle have been suggested as possible factors affecting the distribution of Cysticercus bovis [4].

Economic losses due to bovine cysticercosis are associated with total condemnation of carcasses with generalized infestation and downgrading of carcasses which are subjected to refrigeration, in addition to the cost of refrigeration and extra handling and transport [3]. The treatment cost for human and costs of manufacturing of drugs have significant contribution in estimation of economic losses [7] Although a number of data have been generated on T. aginatal and bovine cysticercosis in different parts of Ethiopia [3,5,8], the current study tries to determine the prevalence, associated risk factors with particular emphasis to the current community perception and knowledge about the disease.

\section{Materials and Methods}

\section{Study area}

The study was conducted from November 2013 to April, 2014 at Adama municipality abattoir in Oromia Regional state. Adama is about 99 kilometers from Addis Ababa and is located at latitude and longitude of $8.55^{\circ} \mathrm{N} 39^{\circ} 27^{\prime} \mathrm{E}$ respectively [9].

\section{Study population}

The study animals for the abattoir survey were indigenous beef cattle brought mainly from central highlands of East Shoa and Awash districts. These are the main sources of meat supply to Adama and surrounding towns. Because of owners' discomfort on multiple incisions during meat inspection by veterinarians for the thorough examination of major muscles, only the masseter muscle and internal organs such as tongue, heart, liver and diaphragm were used as indicators of the presence of cysts in the carcass. For the questionnaire surveys, the target populations were residents and from 4 kebele in Adama town and a total of 200 respondents were participated in this study area. In the drug inventory study, information was gathered from private pharmacies, and hospitals in Adama town.

\section{Study design and sampling}

A cross-sectional study was conducted using routine meat inspection technique for the presence e of C. bovis in cattle slaughtered at Adama municipal abattoir. Meat inspection was made in accordance with Solomon [10] for the detection of Cysticercus bovis. Moreover, a cross-sectional study was conducted by a structured questionnaire survey to assess the prevalence of $T$. saginata and associated risk factors. The sample size for all abattoirs and questionnaire surveys were determined using the formula described by Thrusfield [11] by taking 50\% prevalence (i.e. not known expected prevalence), 95\%

*Corresponding author: Yacob Hailu T, Addis Ababa University, College of Veterinary Medicine and Agriculture, P.O. box 34, Debre-zeit, Ethiopia, Tel: 0251911-476007; Fax: 0251-114-339933; E-mail: yamilaya2008@gmail.com

Received May 13, 2015; Accepted July 09, 2015; Published July 11, 2015

Citation: Tolossa YH, Taha A, Terefe G, Jibat T (2015) Bovine Cysticercosis and Human Taeniosis in Adama Town, Oromia Region, Ethiopia. J Veterinar Sci Technol S10: 003. doi:10.4172/2157-7579.S10-003

Copyright: (c) 2015 Tolossa YH, et al. This is an open-access article distributed under the terms of the Creative Commons Attribution License, which permits unrestricted use, distribution, and reproduction in any medium, provided the original author and source are credited. 
confidence interval and 5\% precision. As a result 384 bovine carcasses were sampled in order to increase precision of sample size. Similarly, by using the formula given by Arsham [12] $\left(0.25 / \mathrm{SE}^{2} \mathrm{SE}=5 \%\right)$, the sample size for the questionnaire survey was expected to be 100 for each kebele. However, a total of 200 individuals were interviewed using structured questioner from each of the four studied kebeles in order to accommodate the different classifications of risk factors. Age of respondents was categorized as (young: $<20$ years of age, and adults: $>20$ years of age). Similarly, religion was broadly classified as Christian and Muslim whereas occupation was subdivided into farmers, merchants, butchers and abattoir workers, civil servants and students. Data were also classified according to education levels of the respondents as illiterate (without formal education), literate (elementary up to high school) and graduates (colleges and universities)

\section{Data analysis}

Abattoir data were collected and recorded on Microsoft Excel spread sheet. The outcome variables for the abattoir study were presence of C. bovis and were analyzed using STATA and associations were analyzed using Chi square test $\left(\mathrm{X}^{2}\right)$. Once a chi-square test was run for the bivariate analysis and after this we built a logistic regression in order to identify risk factors. The prevalence of the disease was determined while various risk factors and the most significant independent variables for cysticercosis in animals and T. saginata in humans.

\section{Results}

\section{Abattoir survey results}

Out of the 384 inspected cattle carcasses, 10 animals had varying number of $C$. bovis with an overall prevalence of $2.6 \%(2.2-3.5 \%)$. Within positive animals, the prevalence of $C$. bovis in the tongue and triceps muscle was much higher than in the liver, masseter and heart. This anatomical distribution of cysticerci showed significant variation $(\mathrm{P}<0.001)$ in different predilection sites as observed in the tongue, triceps muscle, liver, masseter and heart, $40 \%, 24 \%, 10 \%, 6 \%$ $6 \%$ respectively. Among inspected carcasses, in average nine cysts were found in the tongue of one animal.

Of the total 65 cysts collected, $43(66.2 \%)$ were viable while others 22(33.8) were degenerated and dead cysts. The highest number of viable cysts were detected in the tongue 20 (46.5\%), followed by triceps 12 (27.91\%), liver $5(11.6 \%)$ while much lower viable cysts were observed in the masseter $3(6.9 \%)$ and Heart muscles 3 (6.9\%) (Table 1) were encountered.

\section{Questionnaire survey results}

Among the 200 voluntary respondents interviewed from the selected study areas, (91/200) $45.5 \%$ had experienced T. saginata infection, of which (82/91) 90\% and (9/91)10\% reported using modern drugs and traditional medication for treatment respectively.

\begin{tabular}{|c|c|c|c|c|c|}
\hline $\begin{array}{c}\text { Inspected } \\
\text { Site }\end{array}$ & $\begin{array}{c}\text { Frequency } \\
\text { of cyst }\end{array}$ & $\begin{array}{c}\text { No. of } \\
\text { Viable cyst }\end{array}$ & $\begin{array}{c}\text { Percentage } \\
\text { of Viable cyst }\end{array}$ & $\begin{array}{c}\text { No. of } \\
\text { dead cyst }\end{array}$ & $\begin{array}{c}\text { Percentage } \\
\text { of dead cyst }\end{array}$ \\
\hline Tongue & 12 & 20 & 36 & 15 & 30 \\
\hline $\begin{array}{c}\text { Triceps } \\
\text { muscle }\end{array}$ & 4 & 12 & 20 & 3 & 2 \\
\hline Heart & 2 & 3 & 6 & 3 & 4 \\
\hline Liver & 4 & 5 & 8 & 3 & 6 \\
\hline Masseter & 3 & 3 & 8 & 1 & 2 \\
\hline Total & 25 & 43 & 78 & 22 & 42 \\
\hline
\end{tabular}

Table 1: Proportion of infected, viable and non-viable cysts of $C$. bovis in different organs.

\section{Occupation}

The interaction of respondent occupation and prevalence of was evaluated during the interview. Accordingly, it was found that reported cases were more prevalent in civil servants and merchants $(\mathrm{P}=0.002$ and $\mathrm{X}^{2}=49.028$ ) than people from other sectors of occupation (students, butchers and abattoir) (Table 2).

\section{Educational level and raw meat consumption}

Report of T. saginata infection was higher at all educational levels but more significant in high school and above respondents than others (illiterate), informal education and graduates (colleges and universities) $\left(\mathrm{P}=0.001\right.$ and $\mathrm{X}^{2}=13.972$ ) (Table 3 ). It was also significantly high in people with raw meat consumption or "kitfo lebleb" (65.3\%) habit than those who have never consumed $(16 \%)$ raw meat $\left.(\mathrm{P}<0.001) \mathrm{X}^{2}=13.972\right)$ (Table 4).

The logistic regression analysis also shows that occupation and level of education are the most important risk.

Raw beef meat eating habit $(\mathrm{OR}=5.6)$ and occupation were the most significant explanatory variables for the occurrence of $T$. saginata.

\section{Community perception on source, treatment and prevention of taeniosis}

The disease was perceived by butchers (17.6\%), civil servant (57.4\%) and students (25\%). Meanwhile $64.5 \%$ of the respondents believe that the only source of infection is consumption of raw meat, $32.4 \%$ of them reported that it can be transmitted by consumption of raw milk while $3 \%$ of participants of this interview were with no idea about the source of infection by .

As to prevention of the disease is concerned, $97.5 \%$ think that is avoidable out of which $74 \%$ of participants indicated avoiding raw meat is the only way to prevent the disease while only $20.5 \%$ consider the use of modern drugs from pharmacies and remaining 5.5\% suggested other methods such as using toilet, keeping hygiene and the use of traditional remedies. Based on this questionnaire survey, the raw meat consumption level among respondents is 55.5\% (103/200). Concerning treatment, majority of the respondents $(60.7 \%)$ mentioned that modern drugs are effective against $T$. saginata while $15 \%$ of respondents considered effectiveness of traditional remedies such as "Enkoko" (Embelia schimperi), "kosso" (Hagenia abyssinica), "Awachu" and seed of pumpkin. The knowledge of traditional medicine for T. saginata in respondent during this study was not negligible taking into account that Adama is modern town with relatively standard level of life style compared with surrounding cities.

\section{Inventories of pharmaceutical shops}

An inventory of pharmaceutical shops (pharmacies and drug store) was conducted in Adama town. It was noted that the modern taenicidal drug sold in those shops were produced locally or imported from abroad (United states of America, Europe, Far East and some other Africa countries) that the most preferred drugs among customers in Adama were Niclosamide and Mebendazole (Vermox) while Albenedazole and praziquantel were sold mostly when prescribed by physicians. In general, according to information obtained from Adama Red Cross drug store and other drug stores, Niclosamide, Praziquantel, Albendazole and Mebendazole are commonly used for the treatment of ( $T$. saginata) taeniosis in the area. The cost of taenicidal drugs in last 


\begin{tabular}{|c|c|c|c|c|}
\hline \multicolumn{5}{|c|}{ Taeniosis } \\
\hline Occupation & Respondents (n) & Contracted (\%) & chi-square & p-value \\
\hline Merchants & 37 & 20 & & 0.002 \\
\hline $\begin{array}{c}\text { Butchers and } \\
\text { Abattoir workers }\end{array}$ & 24 & 13 & 49.08 & \\
\hline Civil servants & 78 & 25 & & 0.002 \\
\hline Students & 34 & 18 & & \\
\hline Total & 180 & 76 & & \\
\hline
\end{tabular}

Table 2: Prevalence of $T$. saginata based on occupation of respondents.

\begin{tabular}{|c|c|c|c|c|}
\multirow{2}{*}{ Taenicidal drug } & \multicolumn{3}{|c|}{ Years } & \multirow{2}{*}{ Total } \\
\cline { 2 - 4 } & $\begin{array}{c}2011 \\
\text { Worth (ETB) }\end{array}$ & $\begin{array}{c}2012 \\
\text { Worth (ETB) }\end{array}$ & $\begin{array}{c}2013 \\
\text { Worth (ETB) }\end{array}$ & \\
\hline Niclosamide & 6448 & 7648 & 10448 & 24544 \\
\hline Praziquantel & 1993 & 2786 & 3972 & 8751 \\
\hline Albendazole (tab) & 898 & 447 & 4048 & 5393 \\
\hline \begin{tabular}{c} 
Mebendazole (tab) \\
\hline $\begin{array}{c}\text { Albendazole } \\
\text { (Syrup) }\end{array}$
\end{tabular} & 4341 & 5000 & 13024 & 22365 \\
\hline $\begin{array}{c}\text { Mebendazole } \\
\text { (Syrup) }\end{array}$ & 50200 & 50410.66 & 151232 & 251842.66 \\
\hline \multicolumn{2}{|c|}{ Total } & & & $378,609.66$ ETB $^{*}$ \\
\hline
\end{tabular}

*ETB: Ethiopian Birr

Table 3: Inventory of the taenicdal drugs usage from 2011/12-2013 (3 years) in Adama town.

\begin{tabular}{|c|c|c|c|c|}
\hline \multicolumn{5}{|c|}{ Taeniosis } \\
\hline Level of education & Respondents (n) & Contracted (\%) & Chi-Squre & p-value \\
\hline No education & 14 & 12.5 & 13.97 & \\
\hline Informal education & 12 & 10.7 & & \\
\hline High school and above & 54 & 48 & & $0 . .01$ \\
\hline Graduate & 32 & 28 & & \\
\hline Total & 112 & 99.2 & & \\
\hline
\end{tabular}

Table 4: Prevalence of $T$. saginata by level of education of respondents.

three years 2011/12-2013/14 was about 378,609.66 Eth Birr which is currently equivalent to 18,379 . 11 USD (Table 5)

\section{Discussion}

In the present study an overall prevalence of cysticercosis was found to be $2.6 \%$. Similar finding was reported by Stata Corp [13] at Addis Ababa Abattoir and in other endemic areas in Africa and Asia by Opara et al. Munyeme et al. and Garedaghi et al. [14-16]. Higher prevalence compared to current result was reported from other abattoirs in the country: $18.49 \%$ in Addis Ababa abattoir [3] and 26.25\% in Hawassa [5]. This may be associated with low infestation as reported by Dorny et al. [1] or cysticerci could easily be missed as they may not be present on routine cuts since most cases of cysticercosis occur as light infestations. Moreover, according to Pawlowski [8] and Opara [14], in experienced meat inspectors could most likely miss out quite number of viable cysticerci, which blend with the pinkish-red color of the me at and be passed for human consumption. The majority of the findings in Ethiopia were based on surveys carried out on carcasses subjected to routine meat inspection procedures. This can possibly underestimate the incidences reported. Hence, the same limitations with which meat inspection shares globally were reflected in the results of the present study. The current low prevalence might be as a result of extension works conducted by Veterinary and Medical health development workers that have resulted in improvement of hygienic and feeding habit of population in the study area. In the last five years in Ethiopia in the areas where such extension works had been conducted it was observed that $C$. bovis/T. saginata prevalence tend to decrease.
The present abattoir study also revealed that among the organs accessible for detailed inspection, the heart, and tongue and masseter muscle were the most affected. These preferred predilection sites for the cysts of Cysticercus were comparable with earlier reports in Ethiopia [5,17] and various endemic areas in Africa [8,14,18]. Out of 62 examined cysts, 43 (86\%) were viable while $31(42 \%)$ were dead with relatively higher viability among cysts collected from the tongue. This is in agreement with the findings of Abunna et al. [5] who reported 44.2\% live and $65.8 \%$ dead cysts in Hawassa abattoir (South Ethiopia). On the other hand, Kebede et al. [3] recorded $85.6 \%$ viable and $14.4 \%$ degenerated or calcified cysts in North-west Ethiopia.

In this study, Close to half (44.5\%) of the questionnaire survey respondents confirmed that they experienced tapeworm infection at least once in their life. This was manifested by the observation of proglottids in their feces and/or under wear. Because of religious and cultural reasons, pork is not consumed in the study areas as is the case in many parts of Ethiopia. Hence, the proglottids observed were likely to be of $T$. saginata. The overall prevalence of $T$. saginata among humans in Adama town was $44.5 \%$ which is close to the findings of Adugna et al. [19] which was $55.1 \%$ but lower than the findings of Abunna et al. [5]. The reason for the low prevalence of $T$. saginata recorded in this study may be related to the low level of environmental contamination and degree of awareness of different societies about taeniosis transmission as well as possibly due to the difference in the composition of the respondents.

Relatively higher infection with taenia was observed in civil servants. This implies that the frequency of raw beef consumption is higher in the former group of people suggesting the existence of similar risk factors and raw meat consumption practice. Similar findings were reported by previous studies in other parts of the country $[1,3,5]$. These results agree with the report of Murrell KD that indicated as a more common health problem in population/age groups that consume raw meat or undercooked beef meat [2].

The overall proportion of respondents having knowledge of taeniosis as a zoonotic disease was $85.3 \%$. Taeniosis was perceived by $17.6 \%$ of butchers, civil servant $57.4 \%$, students $25 \%$ and $64.5 \%$ farmers as a zoonotic disease transmitted to humans by consuming raw beef meat. In addition to consumption of raw meat, $32.4 \%$ of the respondents reported that it can be transmitted by consumption of raw milk. The infection of cattle by the eggs of $T$. saginata was known only by $44.5 \%(89 / 200)$ of the interviewed persons. Regarding consumption of raw meat, $38.2 \%$ of the respondents have the habit of raw meat consumption. Among those who consume raw meat, $44.5 \%$ of them have been infected by $T$. saginata at least once previously. This is in agreement with awareness level of $82.3 \%$ at Jimma by Megersa [20] but, lower than that of Girma [21] who indicated 89.06\% respondents in Addis Ababa mentioned taeniosis is a zoonotic disease transmitted to humans when raw meat is consumed. The difference in the overall awareness level between the two study sites for the common zoonotic

\begin{tabular}{|c|c|c|c|c|c|c|}
\hline \multirow{2}{*}{ Variables } & & df & p-value & OR & \multicolumn{2}{|c|}{$95 \%$ CI for OR } \\
\cline { 5 - 7 } & & & Lower & Upper \\
\hline Occupation & 2.14 & 1 & 0.002 & 4.7 & 1.24 & 58.8 \\
\hline Level of education & 2.27 & 1 & 0.001 & 4.6 & 1.49 & 63.4 \\
\hline $\begin{array}{c}\text { Consumption of raw } \\
\text { meat }\end{array}$ & 2.15 & 1 & 0.001 & 5.6 & 1.52 & 61.2 \\
\hline
\end{tabular}

DF: Degree of Freedom, OR: Odds Ratio, Cl: Confidence Interval

Table 5: Logistic regression analysis of questionnaire survey. 
Citation: Tolossa YH, Taha A, Terefe G, Jibat T (2015) Bovine Cysticercosis and Human Taeniosis in Adama Town, Oromia Region, Ethiopia. J Veterinar Sci Technol S10: 003. doi:10.4172/2157-7579.S10-003

diseases could be due to variations in the living conditions between the two cities, where in Addis Ababa, as a capital city, information might be acquired more easily than in the current study area.

Infection of $T$. saginata was $13.3 \%, 18.9 \%, 43.3 \%$ and $20.5 \%$ in the butchers and abattoir workers, students, civil servant and merchants respectively. The infection rate in the farmers was significantly lower $(\mathrm{P}<0.05)$ than city residents, whereas sex, age and religion of respondents did not show significant level of variation in the prevalence of taeniosis. However, the probability of getting infected was observed to be associated significantly $(\mathrm{P}<0.05)$ with occupation.

Many of the respondents $(60.7 \%)$ mentioned that traditional medicine was effective against $T$. saginata. Traditional medicine mentioned by respondents was "Enkoko" (Embelia schimperi), "kosso" (Hagenia abyssinica),"Awachu" and seed of pumpkin. The knowledge of traditional medicine for $T$. saginata in the four respondent groups was similar.

In conclusion, bovine cysticercosis caused by C. bovis/T. saginata, are important problems in the study areas. On the other hand, the questionnaire survey revealed that human taeniosis is more prevalent in butchers and abattoir workers and illiterate people whereas the problem is lower in students and farmers. Consumption of raw meat and occupation are the major predisposing risk factors. Intensive meat inspection, appropriate treatment of infected people and the use of latrine has to be encouraged to tackle and reduce the problem in the areas. Further well organized public education in each sector and designing community based control strategies is recommended.

\section{Acknowledgements}

The authors would like to acknowledge the office of the Vice-President for Research of the Addis Ababa University for availing grant through thematic research project "safety of Food of Animal Origin". Thanks also due to all voluntary participants in questionnaire survey and workers as well as management of Adama municipality abattoir.

\section{References}

1. Dorny P, Praet N, Deckers N, Gabriel S (2009) Emerging food-borne parasites Vet Parasitol 163: 196-206.

2. Murrell KD (2005) Epidemiology of taeniosis and cysticercosis. In: Murrel KD (ed), WHO/FAO/OIE. Guideline for surveillance, prevention and control of taeniosis and cyaticercosis. World Health Organization for Animal Health (OIE) Paris, pp. 27-43.

3. Kebede N, Tilahun G, Hailu A (2009) Current status of bovine cysticercosis of slaughtered cattle in Addis Ababa Abattoir, Ethiopia. Trop Anim Health Prod 41: 291-294.

4. Tembo A (2001) Epidemiology of T.saginata,/Cysticercosis in Three-selected Agro climatic Zones in Central Ethiopia. MSc. Thesis, FVM, AAU-Free University of Berlin, Germany and Ethiopia.

5. Abunna F, Tilahun G, Megersa B, Regassa A, Kumsa B (2008) Bovine cysticercosis in cattle slaughtered at Awassa municipal abattoir, Ethiopia: prevalence, cyst viability, distribution and its public health implication. Zoonoses Public Health 55: 82-88.

6. Dorny P, Praet N, Deckers N, Gabriel S (2009) Emerging food-borne parasites Vet Parasitol 163: 196-206.
7. Cabaret J, Geerts S, Madeline M, Ballandonne C, Barbier D (2002) The use of urban sewage sludge on pastures: the cysticercosis threat. Vet Res 33: 575-597.

8. Pawlowski ZS, Murrell KD (2001) Taeniasis and cysticercosis. In: Hui YH, Sattar SA, Murrell KD, Nip WK, Stanfield PS (eds) Food-borne Disease Handbook (2nd Edn) New York: Marcel Dekker, pp: 217-227.

9. Central Statistical Authority (CSA) (2010): Livestock population of Ethiopia Central Statistical Authority, Addis Ababa, Ethiopia.

10. Solomon H (1990) Animal Health Review: 1972-1979. Ministry Of Agriculture of Ethiopia, Compiled report pp: 107-108.

11. Thrusfield M (2005) Veterinary epidemiology (3rdedn) Blackwell Science, Oxford, England, pp: 600.

12. Arsham H (2002) Questionnaire Design and Surveys Sampling, Survey: The Online survey, USA.

13. Stata Corp (2001) Statistical Software Release 7.1. Lake Way Drive. College Station. TX.

14. Opara MN1, Ukpong UM, Okoli IC, Anosike JC (2006) Cysticercosis of slaughter cattle in southeastern Nigeria. Ann N Y Acad Sci 1081: 339-346.

15. Munyeme M1, Munang'andu HM, Muma JB, Nambota AM, Biffa D, et al. (2010) Investigating effects of parasite infection on body condition of the Kafue lechwe (Kobus leche kafuensis) in the Kafue basin. BMC Res Notes 3: 346.

16. Garedaghi Y, Rezaii Saber AP, Saberie Khoroshahi M (2011) Prevalence of bovine Cysticercosis of Slaughtered Cattle in Meshkinshahr Abattoir. Am J Anim Vet Sci 6: 121-124

17. Regassa A, Abunna F, Mulugeta A, Megerssa B (2009) Major metacestodes in cattle slaughtered at Wolaita Sodo Municipal abattoir, Southern Ethiopia: prevalence, cyst viability, organ distribution and socioeconomic implications Trop Anim HIth and Prod 41: 1495-1502.

18. Anosike JC (2001) Some observations on Taenia saginata/cysticercosis in slaughter cattle in Nigeria. Int J Zoonoses 2: 82-89.

19. Adugna T, Yacob H, Getachew T, Dinka A (2013) Prevalence of Bovine Cysticercosis and Human taeniasis in South West Shoa Zone. Ethiop Vet $J$ 17: 121-133.

20. Megersa B, Tesfaye E, Regassa A, Abebe R, Abunna F (2010) Bovine cysticercosis in cattle slaughtered at Jimma Municipal Abattoir, South Western Ethiopia: Prevalence, cyst viability and its socio-economic importance. Vet World 3: 257-262.

21. Girma S, Zewde G, Tafess K, Jibat T (2012) Assessment of awareness on food borne zoonoses and its relation with veterinary public health services in and around Addis Ababa. Epidemiol Public Health 4: 48-51. 